\title{
Valuation of Reliability Index in Distribution Network 13.8 kV
}

\author{
F. Yaser ${ }^{1}$, A. Z. Azriyenni ${ }^{1 *}$, D. Y. Sukma ${ }^{1}$ \\ ${ }^{1}$ Department of Electrical Engineering, Universitas Riau, Pekanbaru, Indonesia \\ *Email: azriyenni@eng.unri.ac.id
}

\begin{abstract}
This study is proposed to calculate and analyses the level of reliability of the $13.8 \mathrm{kV}$ distribution system. To calculate the reliability index based on the reliability index of the value of the failure that occurred. The method used throughout this study is the Reliability Index Assessment (RIA) when this method takes into account momentary interruption. The distribution network is considered as the object of this study has six feeders. Based on blackout data obtained, the reliability index becomes smaller and can be distinguished between permanent and temporary disruptions. The calculation results show the reliability index of SAIDI, SAIDI, and MAIFI based on the type of disturbance; the results of this calculation will be compared with SPLN and IEEE. A comparison of the results of the calculation of SAIFI values from the six feeders analyzed all meet the SPLN and IEEE rules. However, in one of the feeders, the SAIDI index exceeds the established standard, which is 24 hours/year/customer, with the SPLN regulation being 21 hours/year/customer, and the IEEE standard is 2.3 hours/customer/year. Furthermore, the results of an analysis of the MAIFI index for all feeders meet the IEEE standard of 5 times/year/customers.
\end{abstract}

Keywords: Distribution Network, MAIFI, RIA, SAIDI, SAIFI.

Paper type Research paper

\section{INTRODUCTION}

Electrical energy is an essential requirement for human activities. It is necessary to channel energy reliably and sustainable from the generating system to the customer, which consists of generation, transmission, and distribution. In a distribution system is part of an electric power system that serves to provide electricity to customers. Increased production results on the part of consumers require a distribution system that has the appropriate level of reliability. The level of reliability is part of the amount of interference that occurs in the distribution system. Therefore, it is necessary to calculate the level of reliability of the distribution system. In a distribution system, the level of reliability can be observed in the frequency of load termination and how long the load termination occurred. Therefore, to measure the level of authenticity in a distribution system, the necessary indexes are needed. In contrast, the indexes measure the level of reliability in a distribution system, including the System Average Interruption Frequency Index (SAIFI), the System Average Interruption Duration Index (SAIDI), the Momentary Average Interruption Frequency Index (MAIFI) [1][2]. Reliability can be interpreted as the probability of the system or equipment to be able to run its performance correctly, within a specified period, as well as with certain working conditions. Santoso has investigated the reliability of the $20 \mathrm{kV}$ distribution network at the substation using the Failure Mode Effect Analysis (FMEA) [3]. He has calculated the reliability index of having four feeders, namely the SAIFI index and SAIDI. The SAIFI reliability index has 3.2 times/customers/years, while for the SAIDI has 24.8 hours/customers/year [4]. The Monte Carlo method is used to simulate extreme weather disaster processes and to produce disturbance scenarios. Different weight assigned to increase different weight and weight loss is chosen as an index of endurance evaluation [5].

Sailaja et al. Have investigated a comparative evaluation of the reliability index on the 11-kV IEEE-RBTS distribution network in urban, rural, and industrial areas. SAIFI index value in urban areas is 757,441 time/customer/years, SAIDI index value is 587,148 hours/customer/year, CAIDI index value is 0.775 time/ hour/customer, and MAIFI index is 612,739 time/customer/year. SAIFI index in rural areas is 1808,265 time/customer/years, SAIDI index is 6054,537 hours/customer/year, CAIDI index is 3,348 time /hour/customer, and MAIFI index 109,384 time/customer/year. SAIFI index value in industrial areas is 403,430 time/customer/years. SAIDI index value is 375,159 hours/customer/year, CAIDI index 0,930 time/hour/customers, and MAIFI index 119,238 time/customer/year. From the comparison results, industrial areas have better SAIFI and SAIDI values than rural and urban areas. The duration of failure is the longest in rural areas, and the biggest temporary disruption in urban areas is due to a large number of customers and disturbances [3]

Rochman et al. have investigated the level of reliability of the $20-\mathrm{kV}$ distribution network utilizing the Failure Mode Effect Analysis (FMEA) method. They have assessed the comparison of distribution networks before repairing and after repairing. The SAIFI index before improvement was 6.6088 time/customer/year and after 
development was 5.4176 time/customer/year, down 18.02\%. The SAIDI was 7.6737 hours/customer/year, and increase becomes 6.4431 hours /customer/year, down $16.04 \%$. The CAIDI index before the rise was 1.1610 time/hour/ customers and after improvement was 1.1892 time/hour/customer, with a decrease of $2.43 \%$. From these results, it is recommended to add a sectionalize and fuse so that failure and duration can be muted [6].

Ehinomen E. Atimati et al. has published an evaluation of distribution of distribution networks in Rivers State, Nigeria. The index is derived using data obtained from the Port Harcourt Electricity Distribution Company (PHEDC), the Ahoada Business unit and the Agogo Service, Egi Power Distribution network. Performance, approval, and quality of network services are studied. The investigation revealed a system that contained an average of $64.44 \%$ for Ahoada and $74.10 \%$ for EGI compared to the ASAI goal of $99.99 \%$, these values were obtained for Egi Telephone networks by being supplied by turbines that gave signals to increase network distribution, increased investment in electricity production [7].

This study developed an analysis using the Reliability Index Assessment (RIA) technique took into account the momentary interruptions and N-1 contingency calculations for each component. Where N-1 contingency calculations determine the effect of failure on the distribution network if a part was experiencing failure, this study was analyzed with data used from data outages due to failures that occur. Also, it will be compared SAIFI, SAIDI, and MAIFI index with PT. PLN, according to SPLN no 68-2: 1986 and IEEE Std standard 1366-2000 [2][8]. Different steps to improve supply reliability can be evaluated in the proposed method. It uses commonly used reliability indices, such as the System Average Interference Duration Index (SAIDI) and the System Average Interference Frequency Index (SAIFI) [5][9].

\section{METHOD}

The RIA method is an approach used to predict interruption in components or distribution networks based on system topology and data regarding component reliability. The input and output of the RIA method can be observed in Figure 1. The data are located in the form of parameters, and the production is the Reliability Index Assessment [10][11].

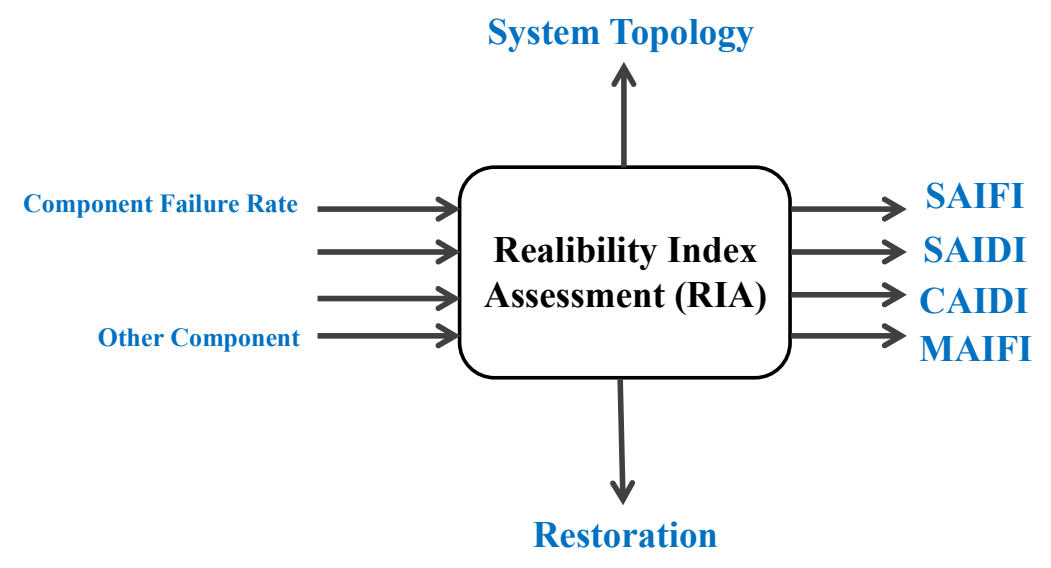

Fig. 1: Concept of the RIA method

RIA records failure that occurs comprehensively on the equipment then identifies the faults and analyses the failure modes. The RIA has used the model system that involves a bottom-up analysis, in which a summary of the specific failure modes at the sub-system [12]. Before the reliability analysis is carried out on a network, it must first determine the components of the reliable data that will be charity. The assessment of the level of reliability can be recognized at how many times the load experienced an extinguishing, how long the outage occurred, and how extensive the failure they can be overcome [1][10]. According to SPLN No. 52-3 1983: 5, there are several levels of how long the recovery of a burden if the interruption, among others [5][11]:

a. Level one; outages for hours, the time needed to locate and repair the damaged part because of the disruption.

b. Level two; outage a few hours, the time required to send officers to the field, localizes interference, and manipulation can turn while on the direction or the other channel.

c. Level three; outage for a few minutes manipulate standby at the substation detection, implementation of the remote.

d. Level four; outage of spontaneous is safety and operation (in a few seconds).

e. Level five; without outages, it has a separate and automatic backup installation. 


\section{SAIFI}

The average extinguishing frequency for each consumer within one year in an area that is evaluated due to sustained interruption. The analytical approach takes into index the reliability index as the number of N-1 contingency contributions from the failure of each component for one year [3]. Mathematically written in equation (1) to equation (2) as follows [5][12][13]:

$$
S A I F I=\sum_{i=1}^{m}\left(S A I F I_{i}^{C}\right)
$$

$\operatorname{SAIFI}_{i}^{C}$ is the number of failure at the load point caused by the negligence of component $\mathrm{i}$,

$$
\operatorname{SAIFI}_{i}^{C}=\frac{\lambda_{i} \cdot S_{i}}{n}
$$

\section{SAIDI}

The average duration of outage for each customer within a year in the area being evaluated. The value is the period of the failure was separated by the number of customers served. The analytical approach takes into the reliability index as a sum of the N-1 contingency contributions from the failure of each component for one year. Mathematically written in equation (3) to equation (4) as follows [5]:[8][12][13]:

$$
\begin{aligned}
& S A I D I=\sum_{i=1}^{m}\left(S A I D I_{i}^{C}\right) \\
& S A I D I_{i}^{C}=\frac{\lambda_{i} \cdot D_{i}}{n}
\end{aligned}
$$

\section{MAIFI}

The average frequency is extinguishing in each customer a year, an area that is evaluated for a momentary interruption. The analytical approach takes into account the reliability index as a sum of the N-1 contingency contributions from the failure of each component for one year, mathematically written in equation (5) through equation (6) as follows [12][13]:

$$
\begin{aligned}
& M A I F I=\sum_{i=1}^{m}\left(M A I F I_{i}^{C}\right) \\
& M A I F I_{i}^{C}=\frac{\lambda_{i} \cdot T_{i}}{n}
\end{aligned}
$$

Determining is the level of reliability at $13.8-\mathrm{kV}$ is consuming the RIA. This method is used for extinguishing data that occurred in the distribution networks, start in the year 2008 until 2012. Then the data are calculated and analyzed to get the reliability index required.

\section{DISTRIBUTION NETWORKS}

Model of network data is used to determine which feeders will be counted, further analyzing each feeder and dividing the calculation are based on the outage of the disturbance and protective equipment that is working. Extinguishing data is used to calculate the level of reliability in the distribution networks. The information is caused types of disruption by the parts of the system to be derived so that the analysis results can be distinguished. The kinds of failures that occur in computing for the distribution network reliability index. There are six feeders in the work area. Each feeder, there is protective equipment used to secure the distribution system on the feeder, following a one-line diagram from one of the feeders [13]. 


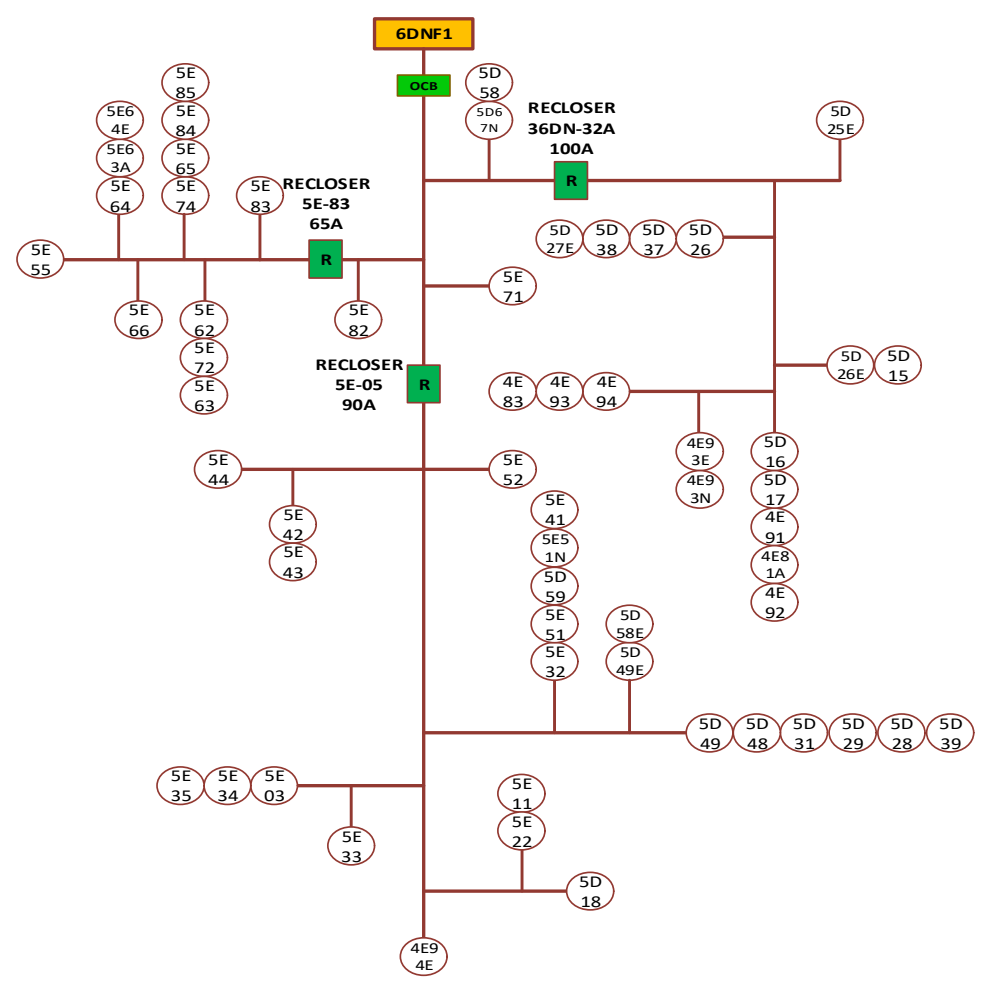

Fig. 2: Model of distribution network

At feeder one in the 6DN substation, it has a network length of $15.65 \mathrm{Km}$, consisting of protection components and distribution networks. The feeder has protective equipment, including; OCB and recloser, to secure interference with downstream. Feeder one is divided into 36 lines. If interference occurs, the protection equipment will trip up to several times the maximum trip.

Table 1. Load point group

\begin{tabular}{clc}
\hline Protection & \multicolumn{1}{c}{ Load point } & Numbers \\
\hline OCB & 5E82 5E71 5D67N 5D58 & 4 \\
& 5E83 5E62 5E84 5E65 5E74 5E64e & \\
& 5E55 5E72 5E63 5E85 5E66 5E64 & 13 \\
R5E-83 & 5E64 & \\
& 5E44 5E42 5E43 5E31 5D18 5E51N & \\
& 5E51 5E32 5D59 5D58e 5D49e & 25 \\
& 5d49e 5D49 5D48 5D29 5D29N & \\
R5E-05 & 5E52 5E35 5E34 5E03 5E33 5E11 & \\
& 5E22 4E94E 5E41 5D39 & \\
& 5D27e 5D38 5D37 4E83 4E93 4E84 \\
& 4E93N 4E93E 5E16 5D17 5E11 & \\
5D25E 5D15 4E94 4E92 4E81A & \\
\hline
\end{tabular}

Feeder two is the number of 47 load points, and the total length of the channel is $19.51 \mathrm{Km}$. If the protective equipment in feeder two is working, there will be a blackout at the load point in each protection equipment. The distribution network in this feeder is divided into 41 lines with different lengths for each line. Protection equipment from OCB that works to secure the feeder three distribution network has been interrupted. If there is a disturbance in feeder three, the protection equipment works, and blackouts occur throughout the load point. The number of load points and a channel length of $2 \mathrm{Km}$ in feeder three will be a blackout at the load point, and then the protective equipment works to secure the network. Table 1 it can be seen that with a total of 59 load points if the protective devices on the feeder work, there will be a blackout on the load point on each protection device that secures it. The total length of the channel is $15.65 \mathrm{Km}$ divided by 36 lines. 
Feeder four has two load points and a total channel length of $2 \mathrm{Km}$ and is divided into two lines. If the protective equipment on feeder four works, there will be a blackout at the load point on each protection device. Feeder five has a distribution network with a channel length of $12.1 \mathrm{Km}$, divided by protective equipment that has 28 load points, namely, customer groups. In feeder five, there is OCB protection equipment that will work if there is interference on the downstream side, which consists of three load points. Feeder six has a distribution network with a channel length of $13.3 \mathrm{Km}$, which has 58 customers into a load point group. Three protection devices work to secure the distribution network on feeder 6 in the event of a disturbance, including OCB protection equipment on the downstream side consisting of 12 load points. The recloser consists of 26 load points, and the $5 \mathrm{D} 112$ recloser consists of 17 load points, and the 6D50 recloser protection equipment has nine load points.

\section{DISCUSSION}

Feeders that will be calculated based on data at the substation, then it will be able to analyze each failure of each component based on data outages from 2008 to 2012. After analyzing the failures that occur and each part experiencing failure, then the parameters needed can be calculated. The parameters obtained for each component are summed based on failure contingency.

Table 2. Parameters of each component

\begin{tabular}{|c|c|c|c|c|c|}
\hline Comp & Length (L) & $\lambda s$ & $\mathbf{r}$ & $\mathbf{U}$ & $\lambda_{M}$ \\
\hline $\mathrm{OCB}$ & 0 & 0 & 0 & 0 & 0 \\
\hline R 5E-83 & 0 & 0 & 0 & 0 & 0 \\
\hline R 5E-05 & 0 & 0 & 0 & 0 & 0 \\
\hline R 36DN-32 & 0 & 0,2 & 7,94 & 1,5872 & 0,2 \\
\hline L1 & 0,10001 & 0,00784 & 0,12 & 0,00094 & 0,01569 \\
\hline $\mathrm{L} 2$ & 0,20001 & 0,01569 & 0,12 & 0,00188 & 0,03137 \\
\hline L3 & 1,09999 & 0,08627 & 0,12 & 0,01035 & 0,17255 \\
\hline L4 & 0,39999 & 0,03137 & 0,12 & 0,00377 & 0,06274 \\
\hline L5 & 0,20001 & 0,01569 & 0,12 & 0,00188 & 0,63137 \\
\hline L6 & 0,20001 & 0,01569 & 0,12 & 0,00188 & 0,03137 \\
\hline L7 & 0,25000 & 0,01961 & 0,12 & 0,00235 & 0,03921 \\
\hline L8 & 0,10001 & 0,00784 & 0,12 & 0,00094 & 0,01569 \\
\hline L9 & 0,25000 & 0 & 0 & 0 & 0,29459 \\
\hline L10 & 2,00001 & 0 & 0 & 0 & 0,95675 \\
\hline L11 & 0,25000 & 0 & 0 & 0 & 0,09459 \\
\hline L12 & 0,20001 & 0 & 0 & 0 & 0,07568 \\
\hline L13 & 0,20001 & 0 & 0 & 0 & 0,07568 \\
\hline L14 & 0,80001 & 0 & 0 & 0 & 0,3027 \\
\hline L15 & 0,40999 & 0 & 0 & 0 & 0,3475 \\
\hline L16 & 2,00001 & 0 & 0 & 0 & 0,71954 \\
\hline L17 & 0,39999 & 0 & 0 & 0 & 0,1439 \\
\hline L18 & 0,10001 & 0 & 0 & 0 & 0,03598 \\
\hline L19 & 0,20001 & 0 & 0 & 0 & 0,07196 \\
\hline L20 & 0,99999 & 0 & 0 & 0 & 0,55976 \\
\hline L2 1 & 0,07001 & 0 & 0 & 0 & 0,02519 \\
\hline L22 & 0,80001 & 0 & 0 & 0 & 0,28782 \\
\hline L23 & 0,07001 & 0 & 0 & 0 & 0,42519 \\
\hline L24 & 0,30002 & 0 & 0 & 0 & 0,10794 \\
\hline L25 & 0,25000 & 0,2 & 0,56 & 0,112 & 0,08994 \\
\hline L26 & 0,20001 & 0,2 & 2,31 & 0,4628 & 0,07196 \\
\hline L27 & 0,30002 & 0 & 0 & 0 & 0,50794 \\
\hline L28 & 0,01500 & 0 & 0 & 0 & 0,0054 \\
\hline L29 & 0,90901 & 0 & 0 & 0 & 0,27705 \\
\hline L30 & 0,22199 & 0 & 0 & 0 & 0,06766 \\
\hline L31 & 0,10001 & 0 & 0 & 0 & 0,03048 \\
\hline L32 & 0,49999 & 0 & 0 & 0 & 0,35239 \\
\hline L33 & 0,45001 & 0 & 0 & 0 & 0,13715 \\
\hline L34 & 0,90001 & 0 & 0 & 0 & 0,27431 \\
\hline L35 & 0,10001 & 0 & 0 & 0 & 0,03048 \\
\hline L36 & 0,10001 & 0 & 0 & 0 & 0,03048 \\
\hline
\end{tabular}

Then, the reliability index of each feeder is calculated at the $6 \mathrm{DN}$ substation. It can be determined the type of failure that occurs. With the method used in this study, the calculation of the reliability level of the distribution system at the 6DN 1 substation feeder. A protection device worked on feeder one within five years; namely, OCB occurred one time a permanent failure and four times a temporary failure. When the $5 \mathrm{E}-83$ recloser protection equipment occurs, eight times a temporary defeat, and the 5E-05 recloser occurs two times a permanent failure and 14 times a temporary failure. Then, the $36 \mathrm{DN}-32$ recloser protection equipment one permanent failure and 
five failure. Table 2 can also be seen the value of the Sustained interruption rate of each component in the feeder, the duration value of the Sustained interruption that occurred, and the value of the momentary interruption rate that happened in each element. Table 3 it can be seen after calculating the reliability index of the N-1 contingency contribution from the failure of each component obtained by the SAIFI index of 0.5017 times/year, the SAIDI index of 1.6563 hours/year, and the value of MAIFI index of 2.6915 times/year. After getting the failure rate and duration of failure and other parameters in each component, then proceed with the calculation of the Lamda at each load point that feels extinguishing from the failure effect of the element. The reliability index can be calculated as the sum of the N-1 contingency contribution from the failure of each of these components can be calculated using equation (1) through equation (6).

Tabel 3. N-1 reliability index for each component

\begin{tabular}{|c|c|c|c|c|}
\hline No & Devices & SAIFI & SAIDI & MAIFI \\
\hline 1 & OCB & 0 & 0 & 0 \\
\hline 2 & Recl. 5E-83 & 0 & 0 & 0 \\
\hline 3 & Recl. 5E-05 & 0 & 0 & 0 \\
\hline 4 & R. $36 \mathrm{DN}-32$ & 0,2 & 1,5872 & 0,2 \\
\hline 5 & L1 & 0,0078 & 0,0009 & 0,0157 \\
\hline 6 & L2 & 0,0157 & 0,0019 & 0,0314 \\
\hline 7 & L3 & 0,0863 & 0,0104 & 0,1725 \\
\hline 8 & $\mathrm{~L} 4$ & 0,0314 & 0,0038 & 0,0627 \\
\hline 9 & L5 & 0,0157 & 0,0019 & 0,6314 \\
\hline 10 & L6 & 0,0157 & 0,0019 & 0,0314 \\
\hline 11 & L7 & 0,0196 & 0,0024 & 0,0392 \\
\hline 12 & L8 & 0,00784 & 0,001 & 0,0157 \\
\hline 13 & L9 & 0 & 0 & 0,0649 \\
\hline 14 & L10 & 0 & 0 & 0,2108 \\
\hline 15 & L11 & 0 & 0 & 0,0208 \\
\hline 16 & L12 & 0 & 0 & 0,0167 \\
\hline 17 & L13 & 0 & 0 & 0,0167 \\
\hline 18 & L14 & 0 & 0 & 0,0667 \\
\hline 19 & L15 & 0 & 0 & 0,0766 \\
\hline 20 & L16 & 0 & 0 & 0,1585 \\
\hline 21 & L17 & 0 & 0 & 0,0317 \\
\hline 22 & L18 & 0 & 0 & 0,0079 \\
\hline 23 & L19 & 0 & 0 & 0,0159 \\
\hline 24 & L20 & 0 & 0 & 0,1233 \\
\hline 25 & L21 & 0 & 0 & 0,0055 \\
\hline 26 & L22 & 0 & 0 & 0,0634 \\
\hline 27 & L23 & 0 & 0 & 0,0937 \\
\hline 28 & L24 & 0 & 0 & 0,0238 \\
\hline$\ldots$ & $\ldots$ & $\ldots$ & $\ldots$ & $\ldots$ \\
\hline \multirow[t]{2}{*}{39} & L35 & 0 & 0 & 0,0088 \\
\hline & $\Sigma$ & 0,5017 & 1,6563 & 2,6915 \\
\hline
\end{tabular}

Table 4 can be seen that based on the previously known reliability level, the reliability of each feeder in the distribution network. The highest SAIFI value is in feeder 2, which is 1,2971 times/year, and the lowest is feeder four because there is never any disruption in the feeder. In contrast, the highest SAIDI value is feeder three, which is 3.84 hours/year due to component failure or damage, so it takes a long time to repair, and the lowest in feeder four. Then for the highest MAIFI value is feeder two that is equal to 5.1921 times/year, and the lowest is in feeder four. At level 1, the best reliability is in feeder four with no interference, and the lowest is in feeder three with level 1 with a duration of disturbance for hours. After obtaining the results of the analysis of the reliability level of the distribution system according to Table 4, then the comparison is then made with the standards set in Indonesia SPLN No. 68-2: 1986 is SAIFI = 3.2 times/year and SAIDI $=21$ hours/year. Then the standards set by IEEE International Std. 1366-2000 is SAIFI = 1.45 times $/$ year and SAIDI 2.3 hours/year.

Table 4. Distribution network reliability level

\begin{tabular}{cccccc}
\hline Feeder & SAIFI & SAIDI & CAIDI & MAIFI & $\begin{array}{c}\text { Reliability } \\
\text { Level }\end{array}$ \\
\hline Feeder 1 & 0,5017 & 1,6563 & 3,301 & 2,6915 & Level 2 \\
Feeder 2 & 1,2971 & 1,5836 & 1,246 & 5,1921 & Level 2 \\
Feeder 3 & 0,2 & 3,84 & 19,2 & 0,4 & Level 1 \\
Feeder 4 & 0 & 0 & 0 & 0 & Level 5 \\
Feeder 5 & 0,2 & 0,0988 & 0,494 & 1,5286 & Level 4 \\
Feeder 6 & 0,1897 & 1,293 & 6,816 & 1,862 & Level 2 \\
\hline
\end{tabular}

Figure 3, the lowest SAIFI index, is in feeder four, and the highest SAIFI value is in feeder two, which is 
1.2971 times/year. From the total amount of all feeders, SAIFI already meets the standards set SAIFI reliability indices SAIFI set SPLN and IEEE. The results of the analysis of the reliability level of the distribution network at the 6DN substation, then the comparison with the SPLN standard No. 68-2: 1986 to SAIFI $=3.2$ times/year and SAIDI $=21$ hours/year. Then a comparison with IEEE Std International standards. 1366-2000 becomes SAIFI = 1.45 times / year and SAIDI 2.3 hours/year. Figure 4 shows the lowest SAIDI index is in feeder four, which is 0 hours/year. While the SAIDI in feeder three is 3.84 hours/year. Based on the comparison of the SAIDI index that has been analyzed with the SPLN and the IEEE standards. It seems that the SAIDI index is still less reliable because it always exceeds the existing standard index. So that the expected reliability index, according to SPLN standards and IEEE standards, has not been achieved.

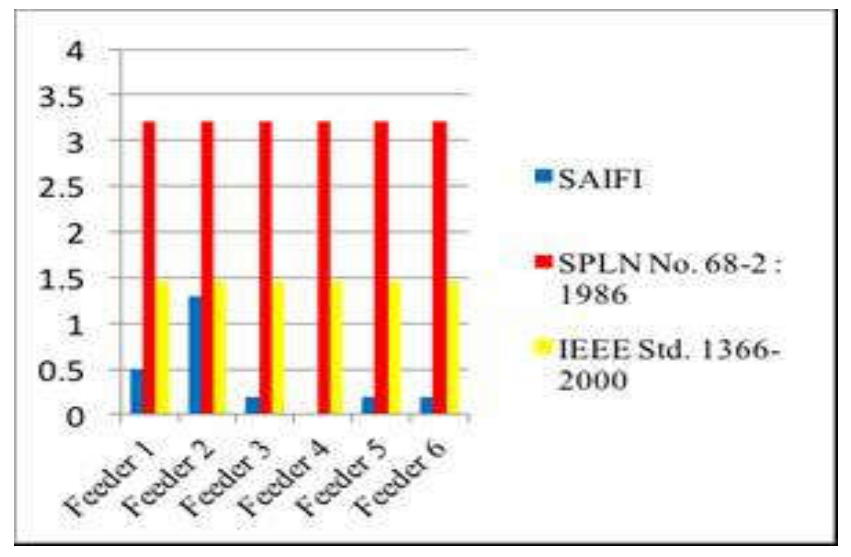

Fig. 3: Reliability index of SAIFI with SPLN and IEEE

After calculating and analysing the reliability index of the distribution system for each feeder using the Reliability Index Assessment (RIA) method, the SAIFI, SAIDI, and MAIFI results are obtained by looking at the contribution of the N-1 contingency assumption to each component. Furthermore, the level of reliability can be analysed based on previous theories; the level of security of each feeder can be seen in Table 6. SAIFI index has been investigated in the distribution network is the result is very reliable. This means that the reliability index is still above IEEE and SPLN, and feeder 4 has a perfect level of authenticity because there is no interference.

Figure 5 can be seen from the results of a comparison of the index with the IEEE standard, has excellent reliability. The lowest MAIFI index is in feeder four because there are no disturbances, the highest MAIFI index is in feeder two, 5.1921 times/year with passing the slight standard of the IEEE set 5 times/year. Comparison of the MAIFI reliability index that has been analysed with the IEEE standard, the measure used is based on the network configuration used at this company. Momentary disturbances that occur in distribution networks cannot be determined precisely by each system, because momentary interruption from each location or lightning that causes a momentary disruption in an area are different.

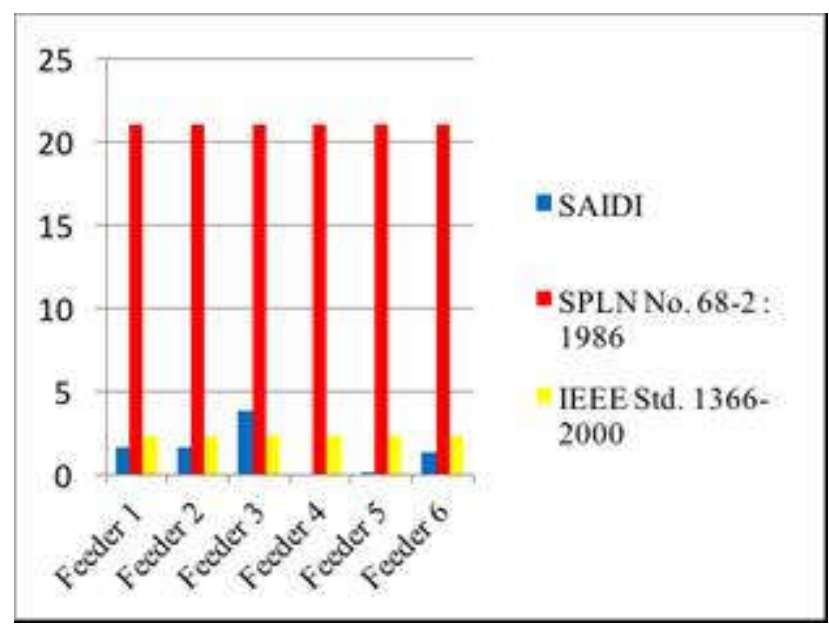

Fig. 4: Reliability index of SAIDI with SPLN and IEEE 


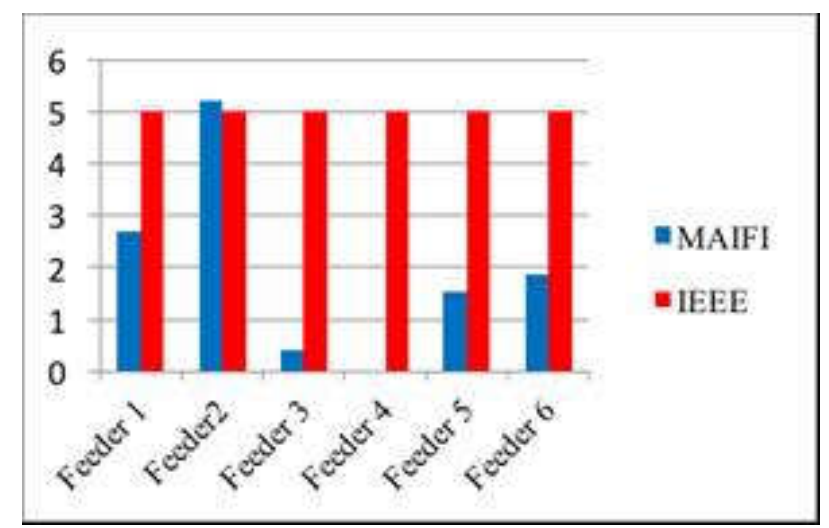

Fig. 5: Comparison in each feeder of Reliability index

\section{CONCLUSION}

Based on the results of the analysis that has been done to calculate the reliability level analysis of the distribution network, the highest SAIFI index value is in feeder two, which is 1.2971 times/year and the lowest SAIFI index is in feeder 4, which is 0 times/year. For the highest SAIDI index value is feeder three, which is 3.84 hours/year, and the lowest SAIDI index is feeder four. The highest MAIFI index value is feeder two, which is 5.1921 times/year, and the lowest MAIFI is feeder four. Finally, the level of reliability in the best is feeder four at level five. Feeder five is good reliable because it is at level four, i.e., extinguished a few minutes. Then feeder one $\&$ two and six is level two with outages for hours, and feeder three the lowest level of reliability with level one.

\section{ACKNOWLEDGEMENT}

The authors would like to thank the Institute for Research and Community Services (LPPM), Universitas Riau, Pekanbaru, Indonesia.

[1] F. Li, "Distributed Processing of Reliability Index Assessment and Reliability-Based Network Reconfiguration in Power Distributed System," vol. 28, no. 1, pp. 230-238, 2005.

[2] N. Liu, T. Wu, T. Xu, and Y. Ma, "Reliability evaluation method for distribution network," in The 6th International Conference on Renewable Power Generation (RPG), vol. 1, pp. 19-20, October, 2017.

[3] Ch.V.S.S.Sailaja, "Evaluation of Reliability Indices using FMEA Technique." 2013.

[4] R. Santoso, "Evaluasi Tingkat Keandalan Jaringan Distribusi 20 kV Pada Gardu Induk Bangkinang Dengan Menggunakan Metode FMEA (Failure Mode Effect Analysis)," 2016.

[5] C. Roduner, S. Karagiannopoulos, E. Taxeidis, and G. Hug, "Reliability and cost assessment methodology of medium-voltage feeders," in 24th International Conference \& Exhibition on Electricity Distribution (CIRED), pp. 2516-2519, June, 2017.

[6] N. M. Rochman, “Analisis keandalan sistem distribusi 20 KV menggunakan Metode RIA pada penyulang KTN 4 Gardu Induk kentungan," 2017.

[7] L. S. Ezema, P. Chiedozie, and E. Ezugwu, "Reliability Indices Evaluation of Distribution Networks for Automation,” Int. J. Power Syst., no. July, 2019.

[8] IEEE-1366-2000, "IEEE Guide for Electric Power Distribution Reliabi," New York, 2012.

[9] Z. Galias, “Tree-Structure Based Deterministic Algorithms for Optimal Switch Placement in Radial," IEEE Trans. Power Syst., vol. 34, no. 6, pp. 4269-4278, 2019.

[10] Disyon, "Analisis Keandalan Sistem Distribusi dengan Metode RIA (Reliability Index Assessment), Studi Kasus: Sistem Distribusi Jawa Timur Penyulang GI Waru,” 2008.

[11] T. Zhang, C. Wang, F. Luo, P. Li, and L. Yao, "Analytical Calculation Method of Reliability Sensitivity Indexes for Distribution Systems Based on Fault Incidence Matrix," J. Mod. POWER Syst. CLEAN ENERGY, vol. 8, no. 2, pp. 325-333, 2020.

[12] T. A, Short, Electric power Distribution Handbook Second Edition. USA, 2014.

[13] Prima, "Analisa Tingkat Keandalan Sistem Gardu Induk 13,8 kV 6DN Minas PT.Chevron Pacific Indonesia dengan Metode Section Technique," 2015. 